\title{
Improving Photovoltaic Performance of ZnO Nanowires Based Colloidal Quantum Dot Solar Cells via $\mathrm{SnO}_{2}$ Passivation Strategy
}

\author{
Shuhei Ozu ${ }^{1}$, Yaohong Zhang ${ }^{1 *}$, Hironobu Yasuda ${ }^{1}$, Yukiko Kitabatake ${ }^{1,2}$, Taro Toyoda $^{1}$, \\ Masayuki Hirata ${ }^{3}, K_{\text {Kenji Yoshino }}{ }^{,}$, Kenji Katayama ${ }^{2}$, Shuzi Hayase ${ }^{4}$, Ruixiang Wang ${ }^{5}$ and \\ Qing Shen ${ }^{1 *}$ \\ ${ }^{1}$ Faculty of Informatics and Engineering, University of Electro-Communications, Tokyo, Japan, ${ }^{2}$ Department of Applied \\ Chemistry, Chuo University, Tokyo, Japan, ${ }^{3}$ Department of Electrical and Electronic Engineering, Miyazaki University, \\ Miyazaki, Japan, ${ }^{4}$ Faculty of Life Science and Systems Engineering, Kyushu Institute of Technology, Fukuoka, Japan, ${ }^{5}$ Beijing \\ Engineering Research Centre of Sustainable Energy and Buildings, Beijing University of Civil Engineering and Architecture, \\ Beijing, China
}

OPEN ACCESS

Edited by:

Sergei Manzhos,

National University of Singapore,

Singapore

Reviewed by:

Zhijun Ning,

ShanghaiTech University, China

Jun Zhu,

Hefei University of Technology, China

*Correspondence:

Yaohong Zhang

yhzhang1021@live.com

Qing Shen

shen@pc.uec.ac.jp

Specialty section:

This article was submitted to

Solar Energy,

a section of the journal

Frontiers in Energy Research

Received: 08 December 2018

Accepted: 30 January 2019

Published: 20 February 2019

Citation:

Ozu S, Zhang Y, Yasuda $\mathrm{H}$, Kitabatake Y, Toyoda T, Hirata M, Yoshino K, Katayama K, Hayase S, Wang $R$ and Shen Q (2019) Improving Photovoltaic Performance of $\mathrm{ZnO}$ Nanowires Based Colloidal Quantum Dot Solar Cells via $\mathrm{SnO}_{2}$ Passivation Strategy. Front. Energy Res. 7:11. doi: 10.3389/fenrg.2019.00011
Colloidal quantum dot solar cells (CQDSCs) based on one-dimensional metal oxide nanowires (NWs) as the electron transport layer (ETL) have attracted much attention due to their larger ETL/colloidal quantum dots (CQDs) contact area and longer electron transport length than other structure CQDSCs, such as planar CQDSCs. However, it is known that defect states in NWs would increase the recombination rate because of the high surface area of NWs. Here, the defect species on the ZnO NWs' surface which resulted in the surface recombination and $\mathrm{SnO}_{2}$ passivation effects were investigated. Comparing with the solar cells using pristine ZnO NWs, the CQDSCs based on $\mathrm{SnO}_{2}$ passivated $\mathrm{ZnO} N W$ electrodes exhibited a beneficial band alignment to charge separation, and the interfacial recombination at the $\mathrm{ZnO} / \mathrm{CQD}$ interface was reduced, eventually resulting in a $40 \%$ improvement of power conversion efficiency (PCE). Overall, these findings indicate that surface passivation and the reduction of deep level defects in ETLs could contribute to improving the PCE of CQDSCs.

Keywords: colloidal quantum dot solar cells, $\mathrm{PbS}, \mathrm{ZnO}$ nanowire, surface passivation, interfacial recombination, $\mathrm{SnO}_{2}$

\section{INTRODUCTION}

Colloidal quantum dots (CQDs) have attracted immense attention due to their applications in the field of optoelectronic devices such as lasers (Hoogland et al., 2006), light-emitting diodes (Wood et al., 2009), and photovoltaic devices due to their bandgap tunability and solution processing (Mcdonald et al., 2005; Nozik et al., 2010; Zhang et al., 2012; Kagan et al., 2016). Colloidal quantum dot solar cells (CQDSCs), a promising contender for new-generation solar cells, have gained more and more attention (Brown et al., 2011; Zhang et al., 2014b, 2016, 2018; Carey et al., 2015; Wang et al., 2016; Hori et al., 2018). CQDs exhibit unique optical and electrical properties, such as an adjustable absorption spectrum and efficient multiple exciton generation (MEG) (Nozik, 2005). To date, the record power conversion efficiency (PCE) value of PbS-based CQDSCs is more than $12 \%$ (Xu et al., 2018). 
In CQDSCs, CQDs work as an active (or a light absorbing) layer, and wide bandgap semiconductors (e.g., $\mathrm{ZnO}, \mathrm{TiO}_{2}$, etc.) are employed as an electron transport layer (ETL). In this architecture, a depletion region was formed near the ETL/CQD interface, which plays a very important role in charge separation and extraction (Choi et al., 2009; Willis et al., 2012). To absorb all incident light, the required thickness of the CQD layer is about $1 \mu \mathrm{m}$ (Wang et al., 2015; Rekemeyer et al., 2016), but the total of depletion width (about $300 \mathrm{~nm}$ ) and carrier diffusion length (about $100 \mathrm{~nm}$ ) of PbS CQDSCs is presently only several hundred nanometers (Zhitomirsky et al., 2013). Thus, thickness of the $\mathrm{PbS}$ CQD layer is usually limited to about $500 \mathrm{~nm}$ even though the light absorption is not enough. Bulk heterojunction (BHJ) architecture is an effective design for solving this absorptionextraction compromise. The $\mathrm{BHJ}$ architecture of CQDSCs is beneficial for extending the depletion region and increasing the thickness of the CQD absorption layer (Barkhouse et al., 2011; Kramer et al., 2012), which can improve both optical absorption and charge collection. One-dimensional $\mathrm{ZnO}$ nanowires (NWs) have been used in BHJ CQDSCs (Wang et al., 2013; Chang et al., 2015; Rekemeyer et al., 2016; Zhang et al., 2017), and the record PCE of $\mathrm{ZnO} \mathrm{NW} / \mathrm{PbS}$ CQD-based CQDSCs has reached $9.6 \%$ (Rekemeyer et al., 2016). However, this strategy would result in large interfacial charge recombination at the $\mathrm{ZnO} N W / C Q D$ interface because of the high surface defect density of $\mathrm{ZnO} \mathrm{NWs}$ (Ehrler et al., 2013; Choi et al., 2017; Cheng et al., 2018; Ding et al., 2018), in turn reducing the PCE of the CQDSCs. Thus, reducing the surface defect density of $\mathrm{ZnO}$ NWs is of critical importance for improving the photovoltaic performance of CQDSCs.

Surface passivation of ETL has proved to be an effective way to eliminate surface defects of ETL and inhibit interfacial recombination at the ETL/light absorber interface in various photovoltaic devices (Hori et al., 2018; Zang et al., 2018). In our previous work, thin amorphous $\mathrm{TiO}_{2}$ was used as a passivation layer to cover the surface of $\mathrm{ZnO}$ NWs, and the interfacial charge recombination at the $\mathrm{ZnO} \mathrm{NW/CQD}$ interface was attenuated in the CQDSCs (Chang et al., 2015). However, that work did not clarify which defect species of $\mathrm{ZnO}$ NWs was suppressed. Furthermore, how the variation of the surface defect state of $\mathrm{ZnO}$ NWs will influence the performance of CQDSCs has not been fully revealed.

Recently, $\mathrm{SnO}_{2}$ has attracted attention not only as an ETL but also as a surface passivation material in solar cells, owing to its unique properties such as wide bandgap $(\sim 3.6 \mathrm{eV})$, low chemical reactivity, high conductivity and good durability in ambient environment (Liu et al., 2016b; Khan et al., 2017; Wang et al., 2017). Herein we report the preparation of $\mathrm{ZnO}$ NW-based PbS CQDSCs and improve the PCEs of the CQDSCs from 5.6 to $7.8 \%$ through a thin amorphous $\mathrm{SnO}_{2}$ surface passivation strategy. The type of defect states of the $\mathrm{ZnO}$ NWs was revealed, and we found that the surface defect density of $\mathrm{ZnO} \mathrm{NWs}$ was reduced after being passivated by $\mathrm{SnO}_{2}$. Due to the enhanced charge separation and reduced interfacial charge recombination efficiencies, the short-circuit current $\left(J_{\mathrm{sc}}\right)$, open-circuit voltage $\left(V_{\mathrm{oc}}\right)$ and fill factor $(F F)$ of $\mathrm{SnO}_{2}$ passivated $\mathrm{ZnO}\left(\mathrm{ZnO} @ \mathrm{SnO}_{2}\right) \mathrm{NW}$-based CQDSCs largely improved more than that of the $\mathrm{ZnO}$ NW-based device, which corresponds to prolonging the effective carrier lifetime ( $\left.\tau_{\text {eff }}\right)$ in the former due to $\mathrm{SnO}_{2}$ passivation. In addition, $\mathrm{ZnO} @ \mathrm{SnO}_{2} \mathrm{NW}$-based CQDSCs can still work efficiently after being stored in air for more than 250 days. Our results indicate that $\mathrm{SnO}_{2}$ surface passivation is an efficient way to improve the performance of $\mathrm{ZnO}$ NW-based CQDSCs.

\section{MATERIALS AND METHODS Synthesis of PbS CQDs}

$\mathrm{PbS}$ CQDs were synthesized by our previous reported method (Zhang et al., 2017). Briefly, a mixed solution of $6 \mathrm{mmol} \mathrm{PbO}$, $15 \mathrm{mmol}$ oleic acid (OA) and $50 \mathrm{ml}$ 1-ocatadecene (ODE) was vigorously stirred and vacuum degassed at room temperature for $30 \mathrm{~min}$ and at $100^{\circ} \mathrm{C}$ for $2 \mathrm{~h}$, respectively. Finally, a clear lead oleate solution was obtained. Under nitrogen flow, $10 \mathrm{~mL}$ hexamethyldisilathiane (TMS)/ODE mixed solution (contained $3 \mathrm{mmol}$ TMS) was rapidly injected into the already synthesized lead oleate solution at $100^{\circ} \mathrm{C}$. After that, when the temperature of $\mathrm{PbS}$ colloid solution reduced to $75^{\circ} \mathrm{C}, \mathrm{a} \mathrm{CdCl}_{2}$ precursor solution [contained $1 \mathrm{mmol} \mathrm{CdCl}, 0.1 \mathrm{mmol}$ tetradecylphosphonic acid (TDPA), and $3 \mathrm{~mL}$ oleylamine (OLA)] was added into the above $\mathrm{PbS}$ solution. Finally, PbS CQDs were collected and purified by a toluene/acetone/methanol solution cleaning and centrifugation process. The PbS CQD precipitate was dried under an $\mathrm{N}_{2}$ flow and finally dispersed in octane $\left(60 \mathrm{mg} \mathrm{mL}^{-1}\right)$.

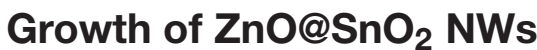

Firstly, ZnO NWs were grown on FTO substrates by a similar method as shown in the literature (Chang et al., 2015). A Sn ${ }^{2+}$ precursor solution was prepared by dissolving $0.2 \mathrm{M} \mathrm{SnCl} 2$ in ethanol and stirring at room temperature for about $30 \mathrm{~min}$. Then, this $\mathrm{Sn}^{2+}$ precursor solution was dropped onto $\mathrm{ZnO}$ NW substrate and spun-cast at 4,000 rpm for $60 \mathrm{~s}$. Finally, the passivated-ZnO NW substrate was heated at $150^{\circ} \mathrm{C}$ for $10 \mathrm{~min}$ and annealed at $400^{\circ} \mathrm{C}$ for $30 \mathrm{~min}$ in air.

\section{Fabrication of PbS CQDSCs}

The PbS CQD active layer was deposited onto the as-prepared NW substrate by a layer-by-layer method as shown in previously (Chang et al., 2015; Nakazawa et al., 2019). After the desired thickness of the PbS CQD layer was obtained, a thin layer of $\mathrm{Au}$ $(\sim 100 \mathrm{~nm})$ was deposited onto the PbS CQD layer by thermal evaporation as the metal electrode.

\section{Characterization}

Field-emission scanning electron microscope (FESEM) (JEOL, JSM-6340) and high-resolution transmission electron microscope (HRTEM) (JEOL, JEM- 2100F) techniques were applied to measure the lengths of the $\mathrm{ZnO} \mathrm{NW}$ and thickness of $\mathrm{SnO}_{2}$ passivation layer. X-ray photoelectron spectroscopy (XPS) (JEOL, S4 JPS-90MX) was used to measure the chemical state of elements, and photoelectron yield spectroscopy (PYS) spectra (Bunkoukeiki, BIP-KV205) were applied to determine the energy levels of NWs and CQDs. Photoluminescence (PL) spectra (JASCO, FP-6500) and UV-vis absorption spectra (HITACHI, U-3900H) were applied to measure the optical properties of NWs. The Hall effect was measured by using the 
Van der Pauw method at room temperature (TOYO ResiTest $8300)$. The photocurrent density-voltage $(J-V)$ measurements of PbS CQDSCs were conducted using a Peccell solar simulator PEC-L10 with a Keithley 2400 source meter. The transient photovoltage (TPV) decay measurements were performed by using a Nd:YAG laser (wavelength $532 \mathrm{~nm}$ ) with a pulse duration of $5 \mathrm{~ns}$ and a pulse frequency of $4 \mathrm{~Hz}$.

\section{RESULTS AND DISCUSSION}

\section{Surface Passivation of ZnO NWs}

After $\mathrm{ZnO} \mathrm{NW}$ growth, $\mathrm{SnO}_{2}$ layers were deposited onto the $\mathrm{ZnO}$ surface by spin-coating $\mathrm{SnO}_{2}$ precursor containing $\mathrm{SnCl}_{2}$. The $\mathrm{SnO}_{2}$ layers were obtained through the hydrolysis and oxidation reaction of $\mathrm{SnO}_{2}$ precursor in the following chemical equation (Marikkannan et al., 2015; Wang et al., 2017; Lu et al., 2018):

$$
\begin{array}{r}
\mathrm{SnCl}_{2}+2 \mathrm{H}_{2} \mathrm{O} \rightarrow \mathrm{Sn}(\mathrm{OH})_{2}+2 \mathrm{H}^{+}+2 \mathrm{Cl}^{-} \\
\mathrm{Sn}(\mathrm{OH})_{2} \rightarrow \mathrm{SnO}+\mathrm{H}_{2} \mathrm{O} \\
2 \mathrm{SnO}+\mathrm{O}_{2} \rightarrow 2 \mathrm{SnO}_{2}
\end{array}
$$

As shown in the above equation, the $\mathrm{SnCl}_{2}$ which is absorbed on the surface of $\mathrm{ZnO}$ NWs firstly changed to $\mathrm{Sn}(\mathrm{OH})_{2}$ through the hydrolysis reaction during or after the spin-coating process. It is worth noting here that the hydroxyl groups on the $\mathrm{ZnO}$ surface may benefit this reaction. Then, after annealing $\mathrm{Sn}(\mathrm{OH})_{2}$ in open atmosphere, the $\mathrm{SnO}_{2}$ layers were formed on the surface of $\mathrm{ZnO}$ NWs. Thus, the absorbed oxygen on the $\mathrm{ZnO}$ surface may be consumed when $\mathrm{SnO}_{2}$ layers are formed. Figure 1 shows a cross-sectional SEM image and TEM image of ZnO NWs with and without $\mathrm{SnO}_{2}$ passivation. It can be clearly seen that the length of $\mathrm{ZnO}$ NWs is approximately $1 \mu \mathrm{m}$ (see Figure 1A), and the morphology of NWs has no change after $\mathrm{SnO}_{2}$ passivation (see Figure 1B). Figures 1C,D show the TEM images of $\mathrm{ZnO}$ $\mathrm{NWs}$ and $\mathrm{ZnO} @ \mathrm{SnO}_{2} \mathrm{NWs}$, respectively. It can be found that the average diameter of $\mathrm{ZnO} \mathrm{NWs}$ is about $40 \mathrm{~nm}$ and a thin amorphous $\mathrm{SnO}_{2}$ layer coated the surface of $\mathrm{ZnO}$ NWs with a thickness of about $2 \mathrm{~nm}$.

We employed XPS to investigate the composition and chemistry state of the surface of $\mathrm{ZnO} \mathrm{NWs}$ and $\mathrm{ZnO} @ \mathrm{SnO}_{2}$ NWs. As shown in Figure 2A, a characteristic peak of $\mathrm{Sn} 3 \mathrm{~d}_{5 / 2}$ at $486.1 \mathrm{eV}$, which belongs to $\mathrm{SnO}_{2}$, was detected in ${\mathrm{ZnO} @ \mathrm{SnO}_{2}}$ NWs (Khan et al., 2017). It indicates that $\mathrm{SnO}_{2}$ was deposited on the surface of $\mathrm{ZnO} \mathrm{NWs}$. The result is well-consistent with the TEM images. In Figure 2B, after fitting, the $\mathrm{O}$ 1s peak of

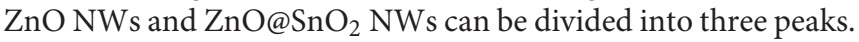
The binding energy peaks assigned to the $\mathrm{O}^{2-}$ state in Metal oxides $\left(\mathrm{O}_{M}\right)$, oxygen vacancy or defects $\left(\mathrm{O}_{D}\right)$ and chemisorbed oxygen or hydroxyl groups $\left(\mathrm{O}_{\mathrm{C}}\right)$ are observed at 529.5, 530.9, and $531.8 \mathrm{eV}$, respectively (Zhang et al., 2014a; Wang et al., 2017). We define the area of these peaks derived from $\mathrm{O}_{M}, \mathrm{O}_{\mathrm{D}}$ and $\mathrm{O}_{\mathrm{C}}$ as $S_{\mathrm{M}}$, $S_{\mathrm{D}}$ and $S_{\mathrm{C}}$. The ratio of $S_{\mathrm{D}} / S_{\mathrm{M}}$ and $S_{\mathrm{C}} / S_{\mathrm{M}}$ roughly corresponds to the weight of each surface defect species in ZnO NWs (Azmi et al., 2016; Yang et al., 2018b). After calculation, we found that the ratio of $S_{\mathrm{D}} / S_{\mathrm{M}}$ was almost the same (from 0.61 to 0.59 ) before and after $\mathrm{SnO}_{2}$ passivation, but the ratio of $S_{\mathrm{C}} / S_{\mathrm{M}}$ was significantly decreased (from 0.14 to 0.05 ) after $\mathrm{SnO}_{2}$ passivation. These results indicate that the density of surface defects which corresponds to $\mathrm{O}_{\mathrm{C}}$ was reduced; this is mainly because of the reduction of chemisorbed oxygen species or hydroxyl groups on the surface of $\mathrm{ZnO} \mathrm{NWs}$ after forming the $\mathrm{SnO}_{2}$ layer.

\section{$\mathrm{PL}$ Spectra of $\mathrm{ZnO} \mathrm{NWs}$ and $\mathrm{ZnO} @ \mathrm{SnO}_{2}$ NWs}

To further reveal the effect of the $\mathrm{SnO}_{2}$ passivation layer, we measured PL spectra of $\mathrm{ZnO} \mathrm{NWs}$ and $\mathrm{ZnO@SnO} \mathrm{NWs}_{2}$ at room temperature. The PL spectra of $\mathrm{ZnO} \mathrm{NWs}$ and $\mathrm{ZnO} @ \mathrm{SnO}_{2} \mathrm{NWs}$ were fitted by using Gaussian functions for understanding the origins of various luminescent components as shown in Figure 3. After fitting, the PL spectra can be divided into seven peaks (Peak A-G) and the centers of those seven peaks are at 3.28 (Peak A), 3.21 (Peak B), 2.98 (Peak C), 2.62 (Peak D), 2.30 (Peak E), 2.17 (Peak F), and $2.03 \mathrm{eV}$ (Peak G). The narrow emission peak in the ultraviolet region (Peak A) corresponding to the intrinsic nearband-edge transition of $\mathrm{ZnO}$ was observed in both $\mathrm{ZnO} \mathrm{NW}$ and $\mathrm{ZnO} @ \mathrm{SnO}_{2} \mathrm{NWs}$ as well. The origin of the violet-to-blue (Peak B, Peak C, and Peak D) region emission is attributed to vacancies or interstitials of zinc, and these defect species were reported to form the shallow level trapping states in ZnO (Djurišić et al., 2010; Vempati et al., 2012; Ding et al., 2018). Notably, the emission ranging from green (Peak E) to orange (Peak $G$ ) is assigned to oxygen-related defects that form deep level trapping states in $\mathrm{ZnO}$, especially at the surface. Green (Peak E), yellow (Peak F), and orange (Peak $\mathrm{G}$ ) emissions are caused by oxygen vacancy, hydroxyl groups, and excess oxygen, respectively (Studenikin et al., 1998; Djurišić et al., 2010; Panigrahy et al., 2010; Vempati et al., 2012; Zhang et al., 2014a). We can estimate the approximate surface defect density of $\mathrm{ZnO}$ from these emissions (Choi et al., 2017; Yang et al., 2018b). In Figure 3A, the PL intensity of greento-orange (from Peak E to Peak G) emission clearly decreased after $\mathrm{SnO}_{2}$ passivation on the $\mathrm{ZnO}$ NWs. This result indicates that the surface defect density of $\mathrm{ZnO}$ NWs was reduced after $\mathrm{SnO}_{2}$ passivation. Furthermore, comparing the area of each PL emission spectrum related to different peaks of $\mathrm{ZnO} \mathrm{NWs}$ and $\mathrm{ZnO} @ \mathrm{SnO}_{2} \mathrm{NWs}$, it can be found that percentages of Peak E, Peak F, and Peak G are decreased after $\mathrm{SnO}_{2}$ passivation (as shown in Tables S1 and Tables S2). This is consistent with the result of XPS measurement, whereby the adsorbed oxygen species and hydroxyl groups on the surface of $\mathrm{ZnO} @ \mathrm{SnO}_{2} \mathrm{NWs}$ are lower than those of $\mathrm{ZnO}$ NWs. Therefore, $\mathrm{SnO}_{2}$ passivation has the potential to suppress the charge recombination through deep level defect states of $\mathrm{ZnO} \mathrm{NWs}$, which originate from the absorbed oxygen and hydroxyl groups.

\section{Energy Band Structure of $\mathrm{ZnO} @ \mathrm{SnO}_{2} \mathrm{NWs}$}

Surface passivation by $\mathrm{SnO}_{2}$ not only has the potential to suppress interfacial recombination at the $\mathrm{ZnO} / \mathrm{CQD}$ interface, but also affects the charge injection from CQDs to $\mathrm{ZnO}$, so it is necessary to understand and select a favorable band alignment of $\mathrm{ZnO}$ and CQDs. First, we measured the absorption spectra of the ZnO NWs, ZnO@SnO 2 NWs, and PbS CQDs (see Figure S1). The optical band gaps $\left(E_{\mathrm{g}}\right)$ of both $\mathrm{ZnO} \mathrm{NWs}$ and $\mathrm{ZnO} @ \mathrm{SnO}_{2}$ NWs are about $3.29 \mathrm{eV}$ (see Figure 4A), and the $E_{\mathrm{g}}$ of $\mathrm{PbS}$ 


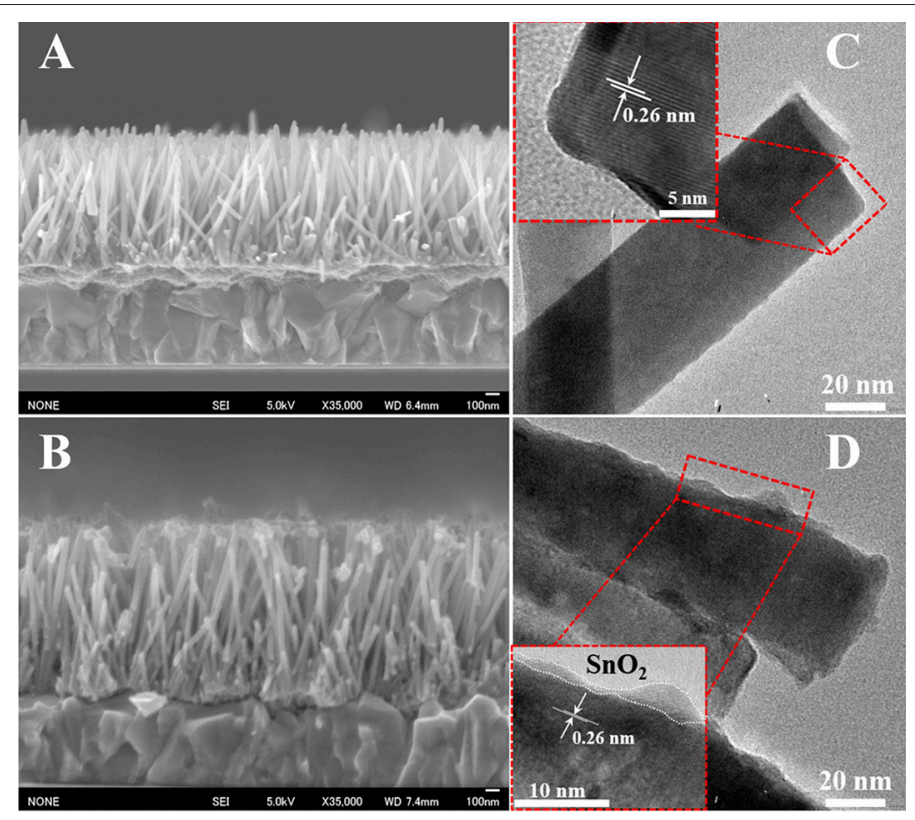

FIGURE 1 | The cross-sectional FESEM images of bare $\mathrm{ZnO} N W s$ (A) and ZnO@ $\mathrm{SnO}_{2}$ NWs (B). TEM images of bare ZnO NWs (C) and ZnO@SnO 2 NWs (D). The

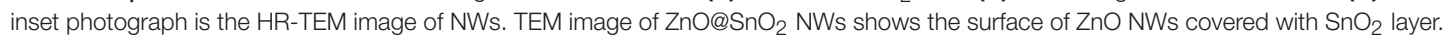
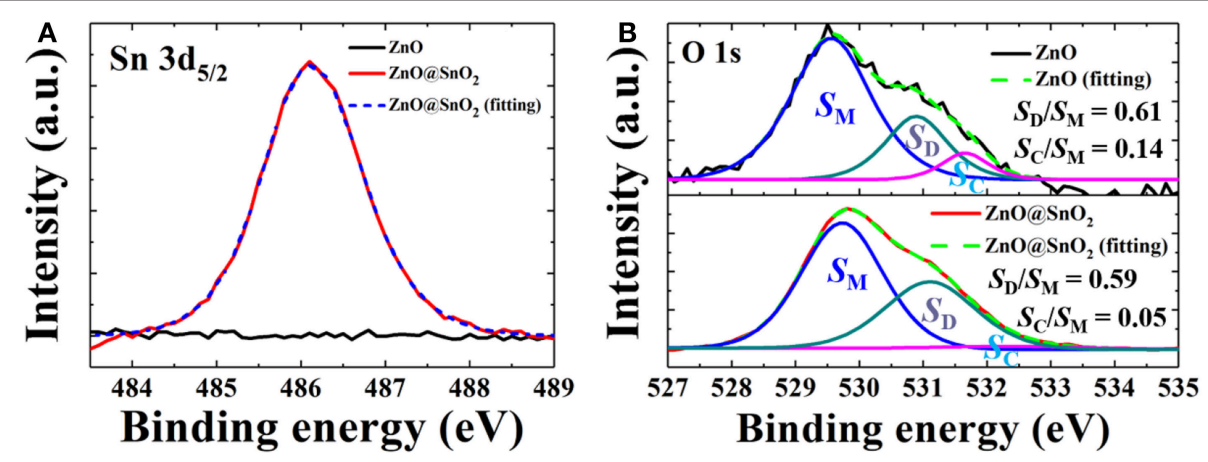

FIGURE 2 | XPS spectra of $\mathrm{ZnO}$ NWs and $\mathrm{ZnO@SnO} 2$ NWs on glass: (A) Sn 3d and (B) O 1s with three resolved O bonding components (blue, green and pink lines).
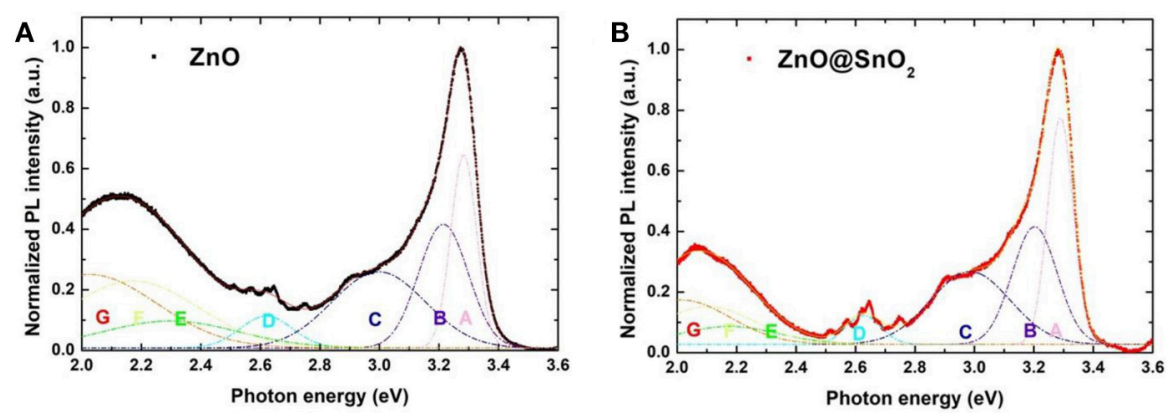

FIGURE 3 | PL spectra with several fitted emission peaks (from Peak A to Peak G): (A) ZnO NWs (B) $\mathrm{ZnO} @ S n O_{2} \mathrm{NWs}$.

CQDs is $1.25 \mathrm{eV}$ (first exciton absorption peak is at $979 \mathrm{~nm}$ ) (see Figure S2). Secondly, the valence band maximum (VBM) of $\mathrm{ZnO} \mathrm{NWs}, \mathrm{ZnO} @ \mathrm{SnO}_{2}$ NWs, and PbS CQDs was measured by PYS technique (see Figure $\mathbf{4 B}$ and Figure S3). The VBM values of $\mathrm{ZnO} \mathrm{NWs}, \mathrm{ZnO} @ \mathrm{SnO}_{2}$ NWs, and $\mathrm{PbS}$ CQDs, which are determined by the intersection of the tangent line and 
the baseline of the PY spectra, are $-7.58,-7.59$, and -5.14 , respectively. Moreover, the conduction band minimum (CBM) of these three samples can be calculated ( $\mathrm{ZnO} \mathrm{NWs:}-4.29 \mathrm{eV}$, $\mathrm{ZnO} @ \mathrm{SnO}_{2} \mathrm{NWs:}-4.30 \mathrm{eV}$, PbS CQDs: $-3.89 \mathrm{eV}$ ) from the $E_{\mathrm{g}}$ and VBM values. Finally, the energy band diagram including the Fermi level $\left(E_{\mathrm{F}}\right)$ of the $\mathrm{ZnO} \mathrm{NWs}, \mathrm{ZnO} @ \mathrm{SnO}_{2} \mathrm{NWs}$ and $\mathrm{PbS}$ CQDs was obtained, as shown in Figure 4C. We calculated $E_{\mathrm{F}}$ of the three samples from their carrier density, which were obtained from Hall effect measurement (as shown in Table S3). Herein, the effective mass of bulk $\mathrm{ZnO}\left(m_{e} \approx 0.24 m_{0}\right)$ and $\mathrm{PbS}\left(m_{h} \approx 0.075\right.$ $m_{0}$ ) were used for calculation (Brus, 1984; Prastowo et al., 2018). It can be seen that the $E_{\mathrm{F}}$ of $\mathrm{ZnO} @ \mathrm{SnO}_{2} \mathrm{NWs}(-4.38 \mathrm{eV})$ is a little higher than that of $\mathrm{ZnO}$ NWs $(-4.46 \mathrm{eV})$, which is mainly due

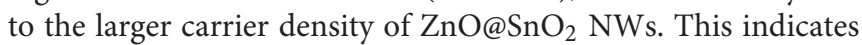

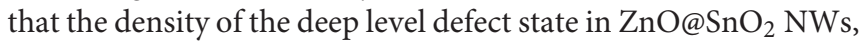
of which the trapped electrons cannot be thermally excited at around room temperature, has decreased compared to that in $\mathrm{ZnO} \mathrm{NWs}$. In addition, the upshift of $E_{\mathrm{F}}$ leads to an increasing of the depletion region width and $V_{\mathrm{oc}}$ in the CQDSCs; there is a possibility that $\mathrm{ZnO} @ \mathrm{SnO}_{2} \mathrm{NWs}$ have a more significant band bending (Liu et al., 2016a; Choi et al., 2017; Yang et al., 2018a), which may lead to an efficient charge separation at the ETL/CQD interfaces. Therefore, $\mathrm{ZnO} @ \mathrm{SnO}_{2} \mathrm{NW}$-based CQDSCs have the potential to achieve a higher PCE than $\mathrm{ZnO} \mathrm{NW}$-based devices because of the improvement in charge separation efficiency and suppression of $\mathrm{ZnO} / \mathrm{CQD}$ interfacial recombination.

\section{Characterization and Photovoltaic Performance of $\mathrm{ZnO} @ \mathrm{SnO}_{2} \mathrm{NWs}$ Based CQDSCs}

Figure 5 shows the schematic diagram of the architecture of CQDSCs and the $J-V$ curves of the CQDSCs; their corresponding performance parameters are shown in Table 1. Cross-section SEM imaging of the $\mathrm{ZnO} @ \mathrm{SnO}_{2} \mathrm{NW} / \mathrm{PbS} \mathrm{CQD} / \mathrm{Au}$ CQDSCs is shown in Figure S3. Compared to the $\mathrm{ZnO} \mathrm{NW}$-based device, $\mathrm{ZnO} @ \mathrm{SnO}_{2} \mathrm{NW}$-based CQDSCs significantly exhibit superior performance. The deposition cycle of the $\mathrm{SnO}_{2}$ layer was optimized and the device based on 2 deposition cycle of $\mathrm{SnO}_{2}$ exhibits the best performance (see Figure S4). As expected from

TABLE 1 | Performance detail of the ZnO NW-based CQDSCs with and without $\mathrm{SnO}_{2}$ passivation layer ${ }^{\mathrm{a}}$

\begin{tabular}{lcccc}
\hline Devices & $\begin{array}{c}\mathbf{J}_{\mathbf{s c}} \\
\left(\mathbf{m A} / \mathbf{c m}^{2}\right)\end{array}$ & $\boldsymbol{V}_{\mathbf{~ o c}}(\mathbf{V})$ & $\boldsymbol{F F}$ & $\boldsymbol{P C E}(\%)$ \\
\hline Without $\mathrm{SnO}_{2}$ & $20.1 \pm 0.3$ & $0.558 \pm 0.040$ & $0.46 \pm 0.01$ & $5.23 \pm 0.28$ \\
& $(20.4)$ & $(0.580)$ & $(0.47)$ & $(5.55)$ \\
With $\mathrm{SnO}_{2}$ & $23.2 \pm 0.7$ & $0.598 \pm 0.006$ & $0.53 \pm 0.02$ & $7.49 \pm 0.27$ \\
& $(23.2)$ & $(0.603)$ & $(0.56)$ & $(7.78)$ \\
\hline
\end{tabular}

All devices were measured under AM1.5 G $100 \mathrm{~mW} / \mathrm{cm}^{2}$ irradiation in air. ${ }^{a}$ Data into the parentheses are parameters of champion devices.
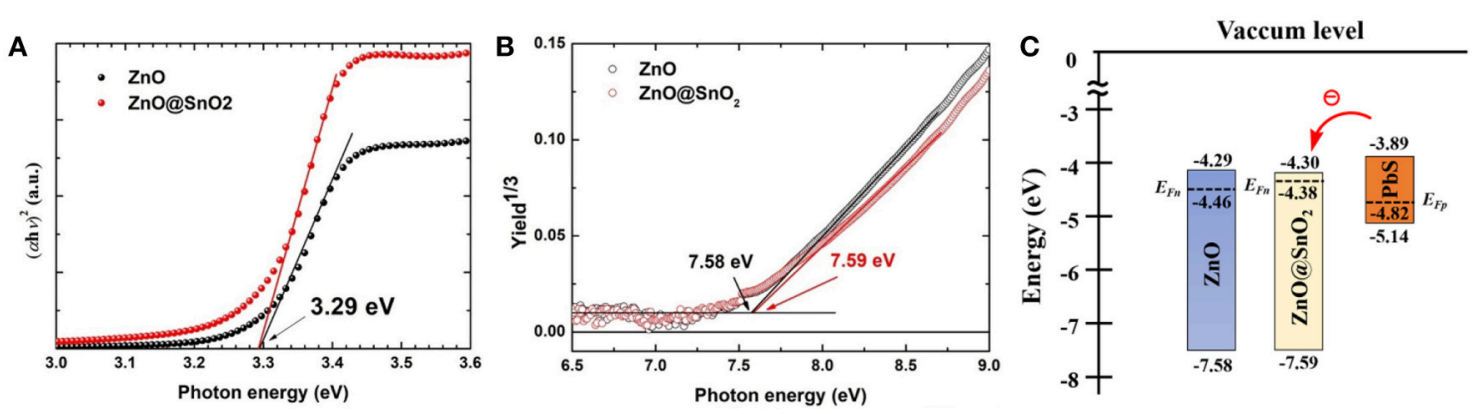

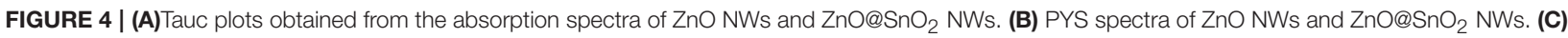
Schematic energy band diagrams of $\mathrm{ZnO} N W s, \mathrm{ZnO} @ S n O_{2} \mathrm{NWs}$, and PbS CQDs.
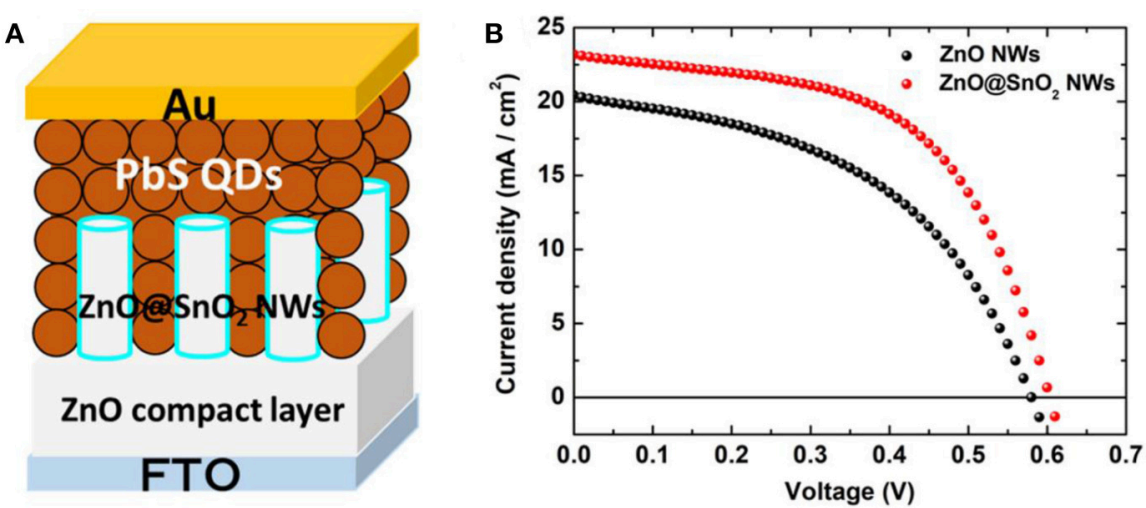

FIGURE 5 | (A)Schematic diagram of the architecture of $\mathrm{ZnO@SnO}_{2}$ NW-based CQDSCs. (B) The $\mathrm{J}$ - $V$ curves of ZnO NW CQDSCs with or without SnO 2 passivation. 
the band alignment in the CQDSCs, the open-circuit voltage $\left(V_{\text {oc }}\right)$ was improved due to the $E_{\mathrm{F}}$ upshift of $\mathrm{ZnO} @ \mathrm{SnO}_{2} \mathrm{NWs}$ and the reduced deep level defect density of $\mathrm{ZnO}$. Meanwhile, enhancement of short-circuit current $\left(J_{\mathrm{sc}}\right)$ and fill factor $(F F)$ of $\mathrm{ZnO} @ \mathrm{SnO}_{2}$ NW-based CQDSCs can be explained by the improvement of charge separation and collection efficiencies, which were caused by the larger band bending and increased depletion region width. IPCE spectra of these devices supported this result (see Figure S5). Particularly, the FF of the $\mathrm{ZnO@SnO} 2$ NW-based CQDSCs improved about 19\% compared to that of the $\mathrm{ZnO} \mathrm{NW}$-based device, which confirms that the charge recombination was considerably suppressed. It is mainly caused by the reduction of surface defects on $\mathrm{ZnO}$ NWs and the reduced leakage current after $\mathrm{SnO}_{2}$ passivation. Consequently, the PCE of $\mathrm{ZnO} @ \mathrm{SnO}_{2}$ NW-based CQDSCs (7.8\%) was enhanced about $39 \%$ more than that of the $\mathrm{ZnO} N W$-based device (5.6\%).

To investigate the detail of the charge recombination mechanism in $\mathrm{ZnO} \mathrm{NW}$ CQDSCs, we have evaluated the diode ideality factor $(n)$ of two types of CQDSCs (Figure 6A). As a reliable parameter of solar cells, the value of $n$ can reflect the charge recombination process in CQDSCs. When interfacial recombination or trap-assisted recombination take over a majority in the recombination process, the value of $n$ should be theoretically larger than unity $(1<n<2)$ (Zhang et al., 2018). The light-intensity $\left(P_{\text {light }}\right)$ dependence of the $V_{\text {oc }}$ has the following relation:

$$
V_{\mathrm{oc}} \propto \frac{n k T}{q}
$$

where $n$ is the diode ideality factor, $k$ is the Boltzmann constant, $T$ is the temperature, and $q$ is elementary charge (Cowan et al., 2010; Gao et al., 2014; Ding et al., 2018). By fitting the $V_{\text {oc }}$ vs. light intensity plotted points, the values of $n$ are determined to be 1.73 and 1.21 for $\mathrm{ZnO}$ NW-based CQDSCs and $\mathrm{ZnO@SnO}{ }_{2}$ NW-based devices, respectively (see Figure 6A). Interfacial recombination or trap-assisted recombination correlated with the deep level defect density in CQDSCs (Ding et al., 2018). In this work, the only difference between the two types of device is the presence or absence of $\mathrm{SnO}_{2}$ passivation, so these results strongly confirm that $\mathrm{ZnO} / \mathrm{CQD}$ interface charge recombination via deep level defect states of the $\mathrm{ZnO}$ NWs was suppressed after $\mathrm{SnO}_{2}$ passivation. To further examine the charge recombination process in CQDSCs, we have measured transient photovoltage (TPV) decay. Figure $\mathbf{S 6}$ shows the TPV decay curves of $\mathrm{ZnO}$ NW CQDSCs with and without $\mathrm{SnO}_{2}$ passivation. TPV decay of $\mathrm{ZnO@SnO} 2 \mathrm{NW}$-based CQDSCs is slower than that of $\mathrm{ZnO}$ NWbased CQDSCs, which confirms that the charge recombination in $\mathrm{ZnO} @ \mathrm{SnO}_{2}$-based devices was weakened. We also investigated the effective carrier lifetime $\left(\tau_{\text {eff }}\right)$ in CQDSCs, and $\tau_{\text {eff }}$ can be defined by the following equation:

$$
\tau_{\text {eff }}=-\frac{\left(\frac{k T}{q}\right)}{\left(\frac{d V_{\text {oc }}}{d t}\right)}
$$

Here, $k$ is the Boltzmann constant, $T$ is the temperature, and $q$ is elementary charge (Zaban et al., 2003; Zhang et al., 2016). As shown in Figure 6B, it shows that the $\tau_{\text {eff }}$ of the CQDSCs was significantly increased after $\mathrm{SnO}_{2}$ passivation, especially at high voltage regions (over $0.25 \mathrm{~V}$ ). This result demonstrates that the charge recombination rate, which is the reciprocal of the carrier lifetime, of the $\mathrm{ZnO} @ \mathrm{SnO}_{2}$ NW-based device decreased in the fast decay process. This result further confirms that $\mathrm{SnO}_{2}$ passivation can significantly attenuate the charge

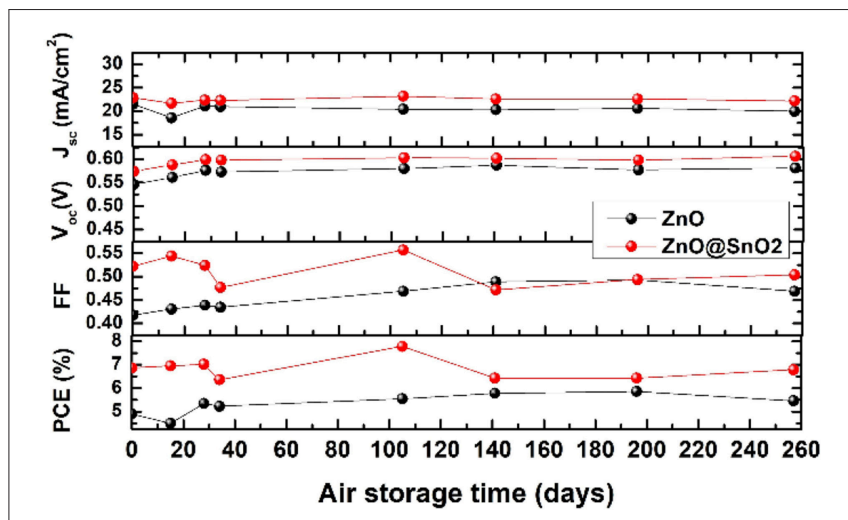

FIGURE 7 | Stability evaluations of $\mathrm{ZnO}$ NWs and $\mathrm{ZnO} @ \mathrm{SnO}_{2} \mathrm{NWs}$ based CQDSCs.
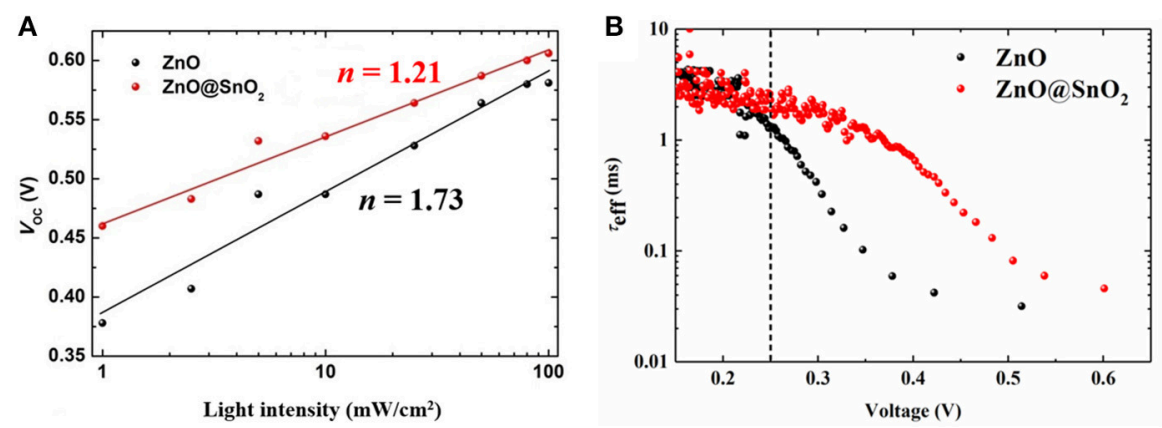

FIGURE 6 | (A) Light-intensity dependence of $V_{\text {oc }}$ for CQDSCs with and without $\mathrm{SnO}_{2}$ passivation. The solid black and red lines are the fitting curves. (B) $\tau_{\text {eff }}$ of CQDSCs with or without $\mathrm{SnO}_{2}$ passivation that was calculated from the TPV decay curves of the devices which were shown in Figure $\mathbf{S 6}$. 
recombination at the $\mathrm{ZnO} N W / C Q D$ interface, and then enhance the performance of the devices, such as $V_{\text {oc }}, F F$, and PCE.

For CQDSCs, stability is important as well as PCE. Thus, the long-term stability of those devices was also evaluated, resulting in them being stored under ambient condition over half year. Both $\mathrm{ZnO} \mathrm{NW}$ - and $\mathrm{ZnO@SnO} 2$ NW-based CQDSCs exhibit excellent stable properties after being stored in air for 250 days, as shown in Figure 7. Therefore, it means that $\mathrm{SnO}_{2}$ passivation can improve the PCE of CQDSCs while it does not impair the long-term stability of devices.

\section{CONCLUSIONS}

In summary, we used $\mathrm{SnO}_{2}$ to passivate the surface of $\mathrm{ZnO}$ NWs and investigated the influence of $\mathrm{SnO}_{2}$ passivation on the defect species of $\mathrm{ZnO}$ and the photovoltaic performance of the $\mathrm{ZnO} \mathrm{NW} / \mathrm{PbS}$ CQDSCs for the first time. We found that $\mathrm{SnO}_{2}$ passivation can reduce the deep level defect density of the $\mathrm{ZnO} \mathrm{NWs}$, which is attributed to the absorbed oxygen and hydroxyl groups on the surface of $\mathrm{ZnO} \mathrm{NWs}$, and in turn reduces the surface recombination and leads to an upward shift of $E_{\mathrm{F}}$. By $\mathrm{SnO}_{2}$ passivation, the PCE of CQDSCs was improved from 5.6 to $7.8 \%$. The $\mathrm{SnO}_{2}$ passivation layer can effectively attenuate the charge recombination at the $\mathrm{ZnO} \mathrm{NW/CQD}$ interface and increase the effective carrier lifetime in CQDSCs. More importantly, $\mathrm{SnO}_{2}$ passivation enhanced the PCE of CQDSCs, while it does not impair the long-term stability of devices. Our study demonstrates that reducing the interfacial recombination at the ETL/CQD interface by using a wide bandgap semiconductor as a passivation layer is an effective way to enhance the performance of CQDSCs.

\section{REFERENCES}

Azmi, R., Oh, S.-H., and Jang, S.-Y. (2016). High-efficiency colloidal quantum dot photovoltaic devices using chemically modified heterojunctions. ACS Energy Lett.1, 100-106. doi: 10.1021/acsenergylett.6b00070

Barkhouse, D. A., Debnath, R., Kramer, I. J., Zhitomirsky, D., Pattantyus-Abraham, A. G., and Levina, L. (2011). Depleted bulk heterojunction colloidal quantum dot photovoltaics. Adv. Mater. 23, 3134-3138. doi: 10.1002/adma.201101065

Brown, P. R., Lunt, R. R., Zhao, N., Osedach, T. P., Wanger, D. D., Chang, L. Y., et al. (2011). Improved current extraction from $\mathrm{ZnO} / \mathrm{PbS}$ quantum dot heterojunction photovoltaics using a MoO3 interfacial layer. Nano Lett. 11, 2955-2961. doi: 10.1021/nl201472u

Brus, L. E. (1984). Electron-electron and electron-hole interactions in small semiconductor crystallites: the size dependence of the lowest excited electronic state. J. Chem. Phys. 80, 4403-4409. doi: 10.1063/1.447218

Carey, G. H., Abdelhady, A. L., Ning, Z., Thon, S. M., Bakr, O. M., and Sargent, E. H. (2015). Colloidal quantum dot solar cells. Chem. Rev. 115, 12732-12763. doi: 10.1021/acs.chemrev.5b00063

Chang, J., Kuga, Y., Mora-Ser,ó, I., Toyoda, T., Ogomi, Y., Hayase, S., et al. (2015). High reduction of interfacial charge recombination in colloidal quantum dot solar cells by metal oxide surface passivation. Nanoscale 7, 5446-5456. doi: 10.1039/C4NR07521H

Cheng, J. J., Chuang, C.-H. M., Hentz, O., Rekemeyer, P. H., Bawendi, M. G., and Gradečak, S. (2018). Dimension- and surface-tailored ZnO nanowires enhance charge collection in quantum dot photovoltaic devices. ACS Appl. Energy Mater. 1, 1815-1822. doi: 10.1021/acsaem.8b00204

\section{SUPPORTING INFORMATION}

Fitting data of PL spectra; optical absorption spectra of $\mathrm{ZnO}$ $\mathrm{NWs}, \mathrm{ZnO} @ \mathrm{SnO}_{2} \mathrm{NWs}$, and PbS CQDs; PYS spectrum of $\mathrm{PbS}$ CQDs treated with CTAB; Absorption and IPCE spectra of devices; $\mathrm{SnO}_{2}$ deposition cycle dependent photovoltaic performances of QDSCs; SEM image of CQDSCs; light-intensity dependence of $J_{\mathrm{sc}}$ for CQDSCs with and without $\mathrm{SnO}_{2}$ passivation; TPV decay curves of ZnO NWs CQDSCs with and without $\mathrm{SnO}_{2}$ passivation.

\section{AUTHOR CONTRIBUTIONS}

SO, YZ, and QS: conceived and designed the experiments; SO, $\mathrm{HY}, \mathrm{YK}$, and MH: performed the experiments; SO, YZ, TT, KK, and QS: analyzed the data; KY, SH, RW, and QS: contributed reagents, materials, analysis tools; $\mathrm{SO}$ : wrote the paper; $\mathrm{YZ}$ and QS: corrected the paper.

\section{FUNDING}

This work was supported by the Japan Science and Technology Agency (JST) CREST and PRESTO programs, Beijing Advanced Innovation Center for Future Urban Design, Beijing University of Civil Engineering and Architecture (Grant UDC2018031121), and the MEXT KAKENHI grant (Grands 26286013, 17H02736).

\section{SUPPLEMENTARY MATERIAL}

The Supplementary Material for this article can be found online at: https://www.frontiersin.org/articles/10.3389/fenrg. 2019.00011/full\#supplementary-material

Choi, J., Kim, Y., Jo, J. W., Kim, J., Sun, B., Walters, G., et al. (2017). Chloride passivation of $\mathrm{ZnO}$ electrodes improves charge extraction in colloidal quantum dot photovoltaics. Adv. Mater. 29:1702350. doi: 10.1002/adma.201702350

Choi, J. J., Lim, Y. F., Santiago-Berrios, M. B., Oh, M., Hyun, B. R., Sun, L., et al. (2009). PbSe nanocrystal excitonic solar cells. Nano Lett. 9, 3749-3755. doi: $10.1021 / \mathrm{nl} 901930 \mathrm{~g}$

Cowan, S. R., Roy, A., and Heeger, A. J. (2010). Recombination in polymerfullerene bulk heterojunction solar cells. Phys. Rev. B 82:245207. doi: 10.1103/PhysRevB.82.245207

Ding, C., Zhang, Y., Liu, F., Kitabatake, Y., Hayase, S., Toyoda, T., et al. (2018). Understanding charge transfer and recombination by interface engineering for improving the efficiency of $\mathrm{PbS}$ quantum dot solar cells. Nanoscale Horizons 3, 417-429. doi: 10.1039/C8NH0 0030A

Djurišić, A. B., Ng, A. M. C., and Chen, X. Y. (2010). ZnO nanostructures for optoelectronics: material properties and device applications. Progr. Q. Electron. 34, 191-259. doi: 10.1016/j.pquantelec.2010.04.001

Ehrler, B., Musselman, K. P., Böhm, M. L., Morgenstern, F. S., Vaynzof, Y., Walker, B. J., et al. (2013). Preventing interfacial recombination in colloidal quantum dot solar cells by doping the metal oxide. ACS Nano 7, 4210-4220. doi: 10.1021/nn400656n

Gao, F., Li, Z., Wang, J., Rao, A., Howard, I. A., Abrusci, A., et al. (2014). Trap-Induced Losses in Hybrid Photovoltaics. ACS Nano 8, 3213-3221. doi: 10.1021/nn501185h

Hoogland, S., Sukhovatkin, V., Howard, I., Cauchi, S., Levina, L., and Sargent, E. H. (2006). A solution-processed $1.53 \mu \mathrm{m}$ quantum dot laser with 
temperature-invariant emission wavelength. Optics Express 14, 3273-3281. doi: 10.1364/OE.14.003273

Hori, K., Zhang, Y., Tusamalee, P., Nakazawa, N., Yoshihara, Y., Wang, R., et al. (2018). Interface passivation effects on the photovoltaic performance of quantum dot sensitized inverse opal TiO2 solar cells. Nanomaterials 8:460. doi: 10.3390/nano8070460

Kagan, C. R., Lifshitz, E., Sargent, E. H., and Talapin, D. V. (2016). Building devices from colloidal quantum dots. Science 353:aac5523. doi: 10.1126/science.aac5523

Khan, J., Yang, X., Qiao, K., Deng, H., Zhang, J., Liu, Z., et al. (2017). Low-temperature-processed $\mathrm{SnO}_{2}-\mathrm{Cl}$ for efficient $\mathrm{PbS}$ quantum-dot solar cells via defect passivation. J. Mater. Chem. A 5, 17240-17247. doi: 10.1039/C7TA05366E

Kramer, I. J., Zhitomirsky, D., Bass, J. D., Rice, P. M., Topuria, T., Krupp, L., et al. (2012). Ordered nanopillar structured electrodes for depleted bulk heterojunction colloidal quantum dot solar cells. Adv. Mater. 24, 2315-2319. doi: 10.1002/adma.201104832

Liu, M., de Arquer, F. P., Li, Y., Lan, X., Kim, G. H., Voznyy, O., et al. (2016a). Double-sided junctions enable high-performance colloidal-quantumdot photovoltaics. Adv. Mater. 28, 4142-4148. doi: 10.1002/adma.201506213

Liu, Q., Qin, M.-C., Ke, W.-J., Zheng, X.-L., Chen, Z., Qin, P.-L., et al. (2016b). Enhanced stability of perovskite solar cells with low-temperature hydrothermally grown $\mathrm{SnO}_{2}$ electron transport layers. Adv. Functional Mater. 26, 6069-6075. doi: 10.1002/adfm.201600910

Lu, S., Zhao, Y., Chen, C., Zhou, Y., Li, D., Li, K., et al. (2018). Sb $\mathrm{SS}_{3}$ Thin-film photovoltaics using aqueous solution sprayed $\mathrm{SnO}_{2}$ as the buffer layer. $A d v$. Electron. Mater. 4:1700329. doi: 10.1002/aelm.201700329

Marikkannan, M., Vishnukanthan, V., Vijayshankar, A., Mayandi, J., and Pearce, J. M. (2015). A novel synthesis of tin oxide thin films by the sol-gel process for optoelectronic applications. AIP Adv. 5:027122. doi: 10.1063/1.4909542

McDonald, S. A., Konstantatos, G., Zhang, S., Cyr, P. W., Klem, E. J., Levina, L., et al. (2005). Solution-processed PbS quantum dot infrared photodetectors and photovoltaics. Nat. Mater. 4:138. doi: 10.1038/nmat1299

Nakazawa, N., Zhang, Y., Liu, F., Ding, C., Hori, K., Toyoda, T., et al. (2019). The interparticle distance limit for multiple exciton dissociation in $\mathrm{PbS}$ quantum dot solid films. Nanoscale Horizons. doi: 10.1039/C8NH00341F. [Epub ahead of print].

Nozik, A. J. (2005). Exciton multiplication and relaxation dynamics in quantum dots: applications to ultrahigh-efficiency solar photon conversion. Inorganic Chem. 44, 6893-6899. doi: 10.1021/ic0508425

Nozik, A. J., Beard, M. C., Luther, J. M., Law, M., Ellingson, R. J., and Johnson, J. C. (2010). Semiconductor quantum dots and quantum dot arrays and applications of multiple exciton generation to third-generation photovoltaic solar cells. Chem. Rev. 110, 6873-6890. doi: 10.1021/cr900289f

Panigrahy, B., Aslam, M., Misra, D. S., Ghosh, M., and Bahadur, D. (2010). Defect-related emissions and magnetization properties of $\mathrm{ZnO}$ nanorods. Adv. Functional Mater. 20, 1161-1165. doi: 10.1002/adfm.200902018

Prastowo, S. H. B., Supriadi, B., Ridlo, Z. R., and Prihandono, T. (2018). Tunneling effect on double potential barriers GaAs and PbS. J. Phys. Conference Series 1008:012012. doi: 10.1088/1742-6596/1008/1/012012

Rekemeyer, P. H., Chang, S., Chuang, C.-H. M., Hwang, G. W., Bawendi, M. G., and Gradečak, S. (2016). Enhanced photocurrent in PbS quantum dot photovoltaics via $\mathrm{ZnO}$ nanowires and band alignment engineering. Adv. Energy Mater. 6:1600848. doi: 10.1002/aenm.201600848

Studenikin, S. A., Golego, N., and Cocivera, M. (1998). Fabrication of green and orange photoluminescent, undoped $\mathrm{ZnO}$ films using spray pyrolysis. J. Appl. Phys. 84, 2287-2294. doi: 10.1063/1.368295

Vempati, S., Mitra, J., and Dawson, P. (2012). One-step synthesis of $\mathrm{ZnO}$ nanosheets: a blue-white fluorophore. Nanoscale Res. Lett. 7:470. doi: 10.1186/1556-276X-7-470

Wang, H., Gonzalez-Pedro, V., Kubo, T., Fabregat-Santiago, F., Bisquert, J., Sanehira, Y., et al. (2015). Enhanced carrier transport distance in colloidal $\mathrm{PbS}$ quantum-dot-based solar cells using $\mathrm{ZnO}$ nanowires. J. Phys. Chem. C 119, 27265-27274. doi: 10.1021/acs.jpcc.5b09152

Wang, H., Kubo, T., Nakazaki, J., Kinoshita, T., and Segawa, H. (2013). PbSquantum-dot-based heterojunction solar cells utilizing $\mathrm{ZnO}$ nanowires for high external quantum efficiency in the near-infrared region. J. Phys. Chem. Lett. 4, 2455-2460. doi: 10.1021/jz4012299
Wang, P., Zhao, J., Liu, J., Wei, L., Liu, Z., Guan, L., et al. (2017). Stabilization of organometal halide perovskite films by $\mathrm{SnO}_{2}$ coating with inactive surface hydroxyl groups on $\mathrm{ZnO}$ nanorods. J. Power Sources 339, 51-60. doi: 10.1016/j.jpowsour.2016.11.046

Wang, R., Shang, Y., Kanjanaboos, P., Zhou, W., Ning, Z., and Sargent, E. H. (2016). Colloidal quantum dot ligand engineering for high performance solar cells. Energy Environ. Sci. 9, 1130-1143. doi: 10.1039/C5EE03887A

Willis, S. M., Cheng, C., Assender, H. E., and Watt, A. A., (2012). The Transitional heterojunction behavior of $\mathrm{PbS} / \mathrm{ZnO}$ colloidal quantum dot solar cells. Nano Lett. 12, 1522-1526. doi: 10.1021/nl204323j

Wood, V., Panzer, M. J., Chen, J., Bradley, M. S., Halpert, J. E., Bawendi, M. G., et al. (2009). Inkjet-printed quantum dot-polymer composites for full-color AC-driven displays. Adv. Mater. 21, 2151-2155. doi: 10.1002/adma.200803256

Xu, J., Voznyy, O., Liu, M., Kirmani, A. R., Walters, G., Munir, R., et al. (2018). 2D matrix engineering for homogeneous quantum dot coupling in photovoltaic solids. Nat. Nanotechnol. 13, 456-462. doi: 10.1038/s41565-018-0117-z

Yang, F., Xu, Y., Gu, M., Zhou, S., Wang, Y., Lu, K., et al. (2018a). Synthesis of cesium-doped $\mathrm{ZnO}$ nanoparticles as an electron extraction layer for efficient $\mathrm{PbS}$ colloidal quantum dot solar cells. J. Mater. Chem. A 6, 17688-17697. doi: 10.1039/C8TA05946B

Yang, J., Lee, J., Lee, J., and Yi, W. (2018b). Suppressed interfacial charge recombination of $\mathrm{PbS}$ quantum dot photovoltaics by graphene incorporated into $\mathrm{ZnO}$ nanoparticles. ACS Appl. Mater. Interfaces 10, 25311-25320. doi: 10.1021/acsami.8b05556

Zaban, A., Greenshtein, M., and Bisquert, J. (2003). Determination of the electron lifetime in nanocrystalline dye solar cells by open-circuit voltage decay measurements. Chem. Phys. Chem. 4, 859-864. doi: 10.1002/cphc.200200615

Zang, S., Wang, Y., Li, M., Su, W., An, M., Zhang, X., et al. (2018). Performance enhancement of $\mathrm{ZnO}$ nanowires/ $\mathrm{PbS}$ quantum dot depleted bulk heterojunction solar cells with an ultrathin $\mathrm{Al}_{2} \mathrm{O}_{3}$ interlayer. Chinese Phys. $B$ 27:018503. doi: 10.1088/1674-1056/27/1/018503

Zhang, X., Qin, J., Xue, Y., Yu, P., Zhang, B., Wang, L., et al. (2014a). Effect of aspect ratio and surface defects on the photocatalytic activity of $\mathrm{ZnO}$ nanorods. Sci. Rep. 4:4596. doi: 10.1038/srep04596

Zhang, Y., Ding, C., Wu, G., Nakazawa, N., Chang, J., Ogomi, Y., et al. (2016). Air stable PbSe colloidal quantum dot heterojunction solar cells: ligand-dependent exciton dissociation, recombination, photovoltaic property, and stability. $J$. Phys. Chem. C 120, 28509-28518. doi: 10.1021/acs.jpcc.6b10920

Zhang, Y., Wu, G., Ding, C., Liu, F., Yao, Y., Zhou, Y., et al. (2018). Lead selenide colloidal quantum dot solar cells achieving high open-circuit voltage with one-step deposition strategy. J. Phys. Chem. Lett. 9, 3598-3603. doi: 10.1021/acs.jpclett.8b01514

Zhang, Y., Wu, G., Mora-Ser,ó, I., Ding, C., Liu, F., Huang, Q., et al. (2017). Improvement of photovoltaic performance of colloidal quantum dot solar cells using organic small molecule as hole-selective layer. J. Phys. Chem. Lett. 8, 2163-2169. doi: 10.1021/acs.jpclett.7b00683

Zhang, Y., Zhu, J., Liu, F., Wu, G., Wei, J., Hu, L., et al. (2014b). $\operatorname{In}_{2} \mathrm{~S}_{3}$ sensitized solar cells with a new passivation layer. J. Photochem. Photobiol. A Chem. 281, 53-58. doi: 10.1016/j.jphotochem.2014.02.012

Zhang, Y., Zhu, J., Yu, X., Wei, J., Hu, L., and Dai, S. (2012). The optical and electrochemical properties of CdS/CdSe co-sensitized $\mathrm{TiO}_{2}$ solar cells prepared by successive ionic layer adsorption and reaction processes. Solar Energy 86, 964-971. doi: 10.1016/j.solener.2012.01.006

Zhitomirsky, D., Voznyy, O., Hoogland, S., and Sargent, E. H. (2013). Measuring charge carrier diffusion in coupled colloidal quantum dot solids. ACS Nano 7, 5282-5290. doi: $10.1021 / \mathrm{nn} 402197 \mathrm{a}$

Conflict of Interest Statement: The authors declare that the research was conducted in the absence of any commercial or financial relationships that could be construed as a potential conflict of interest.

Copyright (c) 2019 Ozu, Zhang, Yasuda, Kitabatake, Toyoda, Hirata, Yoshino, Katayama, Hayase, Wang and Shen. This is an open-access article distributed under the terms of the Creative Commons Attribution License (CC BY). The use, distribution or reproduction in other forums is permitted, provided the original author(s) and the copyright owner(s) are credited and that the original publication in this journal is cited, in accordance with accepted academic practice. No use, distribution or reproduction is permitted which does not comply with these terms. 